\title{
Predatory Capacity and Feeding Preference of Pesticide-Resistant Amblyseius deleoni Muma et Denmark (Mesostigmata: Phytoseiidae)
}

\author{
Bambang Heru Budianto*, Rokhmani and Edi Basuki \\ Faculty of Biology, Jenderal Soedirman University, Purwokerto, Indonesia
}

('Corresponding author's e-mail: bambang.budianto@unsoed.ac.id)

Received: 17 July 2020, Revised: 18 May 2021, Accepted: 19 June 2021

\begin{abstract}
The population of the predatory mites Amblyseius deleoni had been decreasing due to continuous use of synthetic pesticides in tea plantations. Therefore, this study aimed to select pesticide-resistant individuals from a wild-type population of $A$. deleoni and to evaluate whether or not the resistant $A$. deleoni were still sensible as biological control agents. We exposed $A$. deleoni to (propargite), fungicide (copper oxide) and a neem seed extracts. We found that the propargite-resistant predatory mites consumed larvae and nymphs of Tetranychus urticae more than the control (wild type) $(P<0.05)$. There was no difference in the number of eggs and adults of $T$. urticae consumed $(P>0.05)$. The number of individuals of every stage of $T$. urticae consumed by copper-oxide resistant $A$. deleoni was the same $(P>$ $0.05)$. In general, there were no changes in food preference in the resistant predators to the 3 of pesticides $(P>0.05)$. There were slight differences on the pattern of predatory capacity among the resistant predators to the three pesticides. Although the predators are resistant to the 3 pesticides, it took longer to consume their prey in comparison to the control. These findings suggested that pesticide-resistant $A$. deleoni were able to maintain their functions as a biocontrol agent.
\end{abstract}

Keywords: Predatory capacity, Feeding preference, Amblyseius deleoni, Pesticide-resistant

\section{Introduction}

Naturally, the population of one of the most important pests in tea plantations in tropical areas, during dry and rainy seasons, the Scarlet mites Brevipalpus phoenicis is controlled by the predatory mites Amblyseius deleoni Muma and Denmark. However, the effectiveness of these natural predators seemed to have decreased due to continuous uses of synthetic pesticides to control pests and diseases on tea plantations [1]. The predatory behavior and capacity of $A$. deleoni could also change after becoming resistant to various pesticides used in tea plantations in Indonesia [2].

The resistance selection of predatory mites is principally an effort to select individuals in a population that are resistant against pesticides inherited from their previous generations. The character that phenotypically appears in a population will enhance their survival rate in a pesticide-polluted environment. Therefore, a repeating exposure to pesticides will favor the resistant or tolerant individuals than the susceptible ones. This selection process results in an increase in the frequency of pesticideresistant genes, which in turn, will become dominant in a population [3]. The speed of the increase of the frequency of resistant individuals in a population depends on how good the organisms adapt to a pesticide and the mode of action of the pesticides [4].

There have been successes in selecting a permethrin-resistant genus of Amblyseius. Fountain and Medd [5] managed to select resistant generations of A. fallacis, which include 55 generations [6]. Furthermore, Childers \& Denmark [7] and Afshar \& Latifi [8] found that pesticides resistance is inheritable to the descendants through selections. Maroufpoor et al. [9] observed that in A. womersleyi, the levels of resistance against permethrin decreased 20 months after the last exposure.

However, these pesticide-resistant predatory mites still need to be tested in terms of their predatory capacity and behavior to make sure that their power is still sensible as biological control agents. The capacity of a predator is influenced by several factors, namely: the energy to kill the prey, the previous experience with a certain prey $[10,11]$, the density of its prey $[6,12]$ and the preference $[13,14]$.

Several studies found different preferences of predatory A. deleoni to its prey. For example, Phuchalska and Kozak [15] and Parsa et al. [16] found that predatory A. deleoni prefers to prey 
Brevipalpus phoenicis (the scarlet mites) than other types of mites, while Mutisya et al. [17] found that $A$. deleoni prefers to prey Eriophyidae (gall mites) than other mites including B. phoenicis. The difference in preference indicates that $A$. deleoni may have the ability to select the most suitable prey in certain or different conditions. The feeding behavior of predatory mite A. deleoni may therefore change as a result of selection after being exposed to various pesticides used in tea plantations.

Considering that the modes of actions of acaricides vary depending on the contents, these may influence the behavior and capacity of predatory mites. For example, propargite, an acaricide that belongs to a phenoxy group, can cause damage in the respiratory system. The mode of action of this acaricide is "residual killing action" that inhibits cholinesterase in acetylcholine hydrolysis into choline and acetate [18]. Contact Copper Oxide $\left(\mathrm{C}_{\mathrm{u}} \mathrm{O}\right)$ fungicide can impair the permeability of the cuticle and change the action site of its enzyme that reduces the affinity of $\mathrm{Cu}^{2+}$ [5]. On the other hand, neem extract (Azadirachta indica) has diverse effects, because not only that it is consisted of azadirachtin as the major component, but its extract also contains salannin, nimbin, 6-desacetylnimbin, salannidolide, salanninolactone and intermediates [18]. The neem extracts, especially azadirachtin, acts as a strong antifeedant and "insect growth regulator" and can modify the behavior of target organisms [19,20].

Based on the above-mentioned mode of actions of pesticides, the toxicity of pesticide on predatory mites $A$. deleoni may differ from 1 pesticide to another. Therefore, the mites may respond differently, and may show different levels of tolerance or resistance, or may also change their feeding behavior. Accordingly, there is a possibility that the selection pressure from generation to generation will change the feeding preference and therefore the predatory levels of $A$. deleoni needs to be further studied.

Currently, there is neither information regarding the resistance against pesticides nor the predatory capacity and behavior of $A$. deleoni after becoming resistant to various pesticides. Therefore, this study aimed to select pesticide-resistant individuals from a wild-type population and to evaluate whether or not the selected $A$. deleoni population had changed their predatory capacity and behavior after being exposed to acaricide (propargite), fungicide $\left(\mathrm{C}_{\mathrm{u}} \mathrm{O}\right)$ and a neem seed extract. These efforts will improve the survival rate of the important biological control agent Amblyseius deleoni in pesticide-polluted plantations.

\section{Materials and methods}

\section{Parental-mite population}

The parental of $A$. deleoni mites used in this study were taken from a wild type population from Gambung Village, West Java, Indonesia at the coordinate of $107^{\circ} 29^{\prime} 32^{\prime \prime}$ - 107 $31^{\prime} 11^{\prime \prime}$ East Longitude and $07^{\circ} 07^{\prime} 18^{\prime \prime}-07^{\circ} 09^{\prime} 11^{\prime \prime}$ South Latitude, with the altitude of $1.350 \mathrm{~m}$ above sea level. This area is an isolated tea plantation where no pesticides were used. These mites were tested for its resistance level by selecting the most vulnerable population indicated by the narrowest range of fiducial limit (FL). The selected mites were designated as the parent population with the resistance ratio (RR) equals to 1 .

\section{Resistance selection}

The resistance selections were performed in the Entomology and Parasitology Laboratory of Faculty of Biology, Universitas Jenderal Soedirman, Indonesia. The wild-type predatory mites, A. deleoni were exposed to a gradient of concentrations of pesticides to obtain $\mathrm{LC}_{50}$ as the basis of selection. The concentrations of $0,285,570,855$ and $1140 \mathrm{ppm}$ of propargite acaricide were applied to the wild-type samples, Filial $1=\mathrm{F} 1 /$ Generation 1 until F5/Generation 5 of predatory mites $A$. deleoni. Exposures to $\mathrm{C}_{\mathrm{u}} \mathrm{O}$ fungicide of $0,10,100,1000$ and $10000 \mathrm{ppm}$ were performed on the parent samples, F1 to F4, while the concentrations of samples F5 to F12 were increased to $200000 \mathrm{ppm}$. The resistance selection of $A$. deleoni against neem seed extracts, with concentrations of $0,25,50,75$ and $100 \%$, were applied on the Parent to F8. Ten A. deleoni mites were exposed to each concentration of pesticides with 6 replicates.

\section{Preference and predatory-capacity test}

The resistant generations of predatory mites $A$. deleoni, resulting from the experiments, were then tested for possible changes in their feeding behavior. The tests included free-choice feeding preference on several alternative prey. The resistant predatory mites were fed on tea pollens, red bean pollens, and $T$. urticae and Tyrophagus sp. For preference tests, with 6 replicates. The predatory capacity tests of the resistant $A$. deleoni included feeding treatments on the eggs, larvae, nymphs and adults of $T$. urticae. Every treatment was repeated 6 times. 


\section{Data analysis}

The data of resistance levels to pesticides were analyzed using a computer application Probit and Logit (POLO). This application was employed to analyze the lethal concentrations 50 (LC $\mathrm{L}_{50}$ ) with $95 \%$ $\mathrm{FL}$, the RR, the slope and the standard errors (SE) and $\chi^{2}$ at 0.05 error level. The resistant generations of predatory mites $A$. deleoni, resulted from the experiment were indicated by a non-overlapping range of a FL.

The data of feeding preferences and the predatory capacity of the resistant generations of predatory mites $A$. deleoni were conducted using a Completely Randomized Design and analyzed statistically using Analysis of Variance, with error level of 0.05 and 0.01 and followed by Least Significant Difference tests with the same error level.

\section{Results and discussion}

The results showed that $\mathrm{LC}_{50}$ of the wild-type $A$. deleoni against a gradient of concentrations of propargite of $483.46 \mathrm{ppm}$ were ranging from 419.61 to $547.52 \mathrm{ppm}$ (Table 1).

Table 1 Resistance tests of parent Amblyseius deleoni against propargite on the wild-type population.

\begin{tabular}{lcccc}
\hline Generation & $\mathbf{N}$ & $\begin{array}{c}\text { Range of concentrations } \\
(\mathbf{p p m})\end{array}$ & $\mathbf{L C}_{\mathbf{5 0}}(\mathbf{9 5}$ \% FL) (ppm) & Slope \pm SE (ppm) \\
\hline Wild type & 300 & $0.00-1140$ & $\begin{array}{c}483.46 \\
(419.61-547.52)\end{array}$ & $5.12 \pm 0.53$ \\
\hline
\end{tabular}

Table 1 also shows that the resistance levels of the parent population against propargite were more or less the same. The steep mortality data indicated that this range of concentrations was still tolerable by only a small portion of individual mites in the wild-type population. Therefore, the most vulnerable population was then designated as the parent population that presumably had never been exposed to any pesticide. Thus, the results of the selection on the wild-type population were then used in the subsequent experiments as a standard parent $(\mathrm{RR}=1)$. Souza-Pimentel et al. [21] found a similar result that the predatory mite Neoseiulus californicus was highly tolerant to the acaricide-insecticide than the recommended concentration for the use in citrus. This may be due to the fact both Amblyseius deleoni and Neoseiulus californicus are both from the same Family, so that they have similar character.

The subsequent resistance selections of $A$. deleoni against propargite acaricide found that the resistance character was $1^{\text {st }}$ noticeable in the $4^{\text {th }}$ generation $(F 4)$, and then increased to reach the ratio of 7.36 times in the $16^{\text {th }}$ generation (F16), compared to that of the parent population. The increasing resistance of $A$. deleoni against propargite from Parent $(\mathrm{P})$ to the $16^{\text {th }}$ generation (Table 2 ).

Table 2 The increasing resistance of Amblyseius deleoni against propargite from Parent generation (P) to $16^{\text {th }}$ generation (F16).

\begin{tabular}{|c|c|c|c|c|}
\hline Generation & $\begin{array}{c}\mathrm{LC}_{50}(95 \% \mathrm{FL}) \\
(\mathrm{ppm})\end{array}$ & $\begin{array}{c}\text { Resistance } \\
\text { Ratio }\end{array}$ & $\begin{array}{l}\text { Slope } \pm \text { SE } \\
\quad(\mathbf{p p m})\end{array}$ & $\chi^{2}(\mathbf{d f}=22)$ \\
\hline $\mathrm{P}$ & $483.46(419.61-547.52)^{\mathrm{a}}$ & 1 & $5.12 \pm 0.53$ & 35.21 \\
\hline $\mathrm{F} 1$ & $517.57(452.86-583.31)^{a}$ & 1.07 & $5.39 \pm 0.55$ & 35.43 \\
\hline $\mathrm{F} 2$ & $566.96(513.91-620.86)^{\mathrm{a}}$ & 1.17 & $5.007 \pm 0.52$ & 20.24 \\
\hline F3 & $596.14(532.94-662.14)^{a}$ & 1.23 & $4.025 \pm 0.46$ & 20.71 \\
\hline $\mathrm{F} 4$ & $799.17(677.04-986.02)^{b}$ & 1.65 & $2.328 \pm 0.41$ & 10.37 \\
\hline F5 & $1265.94(1000.30-2006.56)^{c}$ & 2.62 & $2.121 \pm 0.44$ & 5.83 \\
\hline F6 & $1704.94(1517.08-2129.70)^{\mathrm{c}}$ & 3.53 & $4.015 \pm 0.83$ & 3.78 \\
\hline F7 & $2035.12(1821.59-2211.90)^{c}$ & 4.21 & $4.689 \pm 1.27$ & 6.41 \\
\hline F8 & $2546.38(2648.48-2462.90)^{\mathrm{d}}$ & 5.27 & $12.075 \pm 1.67$ & 3.97 \\
\hline F9 & $2851.47(2753.30-2981.23)^{\mathrm{e}}$ & 5.89 & $11.223 \pm 1.78$ & 5.17 \\
\hline F10 & $3086.59(2999.20-3190.77)^{f}$ & 6.38 & $13.749 \pm 1.99$ & 9.04 \\
\hline F11 & $3296.36(3220.90-3376.48)^{\mathrm{g}}$ & 6.82 & $17.706 \pm 2.26$ & 10.14 \\
\hline F12 & $3340.01(3258.10-3408.52)^{\mathrm{g}}$ & 6.91 & $21.214 \pm 2.73$ & 8.64 \\
\hline
\end{tabular}




\begin{tabular}{|c|c|c|c|c|}
\hline Generation & $\begin{array}{c}\mathbf{L C}_{50}(\mathbf{9 5 \%} \text { FL) } \\
(\text { (ppm) }\end{array}$ & $\begin{array}{c}\text { Resistance } \\
\text { Ratio }\end{array}$ & $\begin{array}{c}\text { Slope } \pm \text { SE } \\
(\text { ppm) }\end{array}$ & $\chi^{2}(\mathbf{d f}=\mathbf{2 2})$ \\
\hline F13 & $3449.32(3377.90-3516.20)^{\mathrm{g}}$ & 7.13 & $21.586 \pm 2.63$ & 11.34 \\
\hline F14 & $3507.13(3428.30-3568.12)^{\mathrm{g}}$ & 7.25 & $29.400 \pm 4.06$ & 9.63 \\
\hline F15 & $3554.78(3483.50-3613.61)^{\mathrm{g}}$ & 7.35 & $29.257 \pm 3.78$ & 11.48 \\
\hline F16 & $3557.53(3478.70-3621.14)^{\mathrm{g}}$ & 7.36 & $26.506 \pm 3.44$ & 14.23 \\
\hline
\end{tabular}

Note: The number (N) of individuals each generation was 300. FL (Fiducial Limit) is the upper and lower limits of the range of pesticide concentrations with a confidence limit of $95 \%$. The values of $95 \% \mathrm{FL}$ followed by the same small letters, indicated that there is no significant difference, based on statistical tests using POLO $(P>0.05)$.

These findings (Table 2) showed that the resistance character was inherited from their parent population. This result is in line with the study by Silva et al. [3] who studied compatibility of pesticides with the generalist predatory mite Amblyseius largoensis. Propargite is a selective acaricide because exposures to predatory mites Phytoseiulus persimilis resulted in lower mortality, thus, this pesticide is recommended to control the population of pest mites T. urticae, which is the prey of $P$. persimilis $[11,20]$.

In contrast to the results of exposure to propargite, the exposure of wild-type A. deleoni to $56 \%$ $\mathrm{C}_{\mathrm{u}} \mathrm{O}$ in this study resulted in that the range of the $\mathrm{FL}$ of $\mathrm{LC}_{50}$ was narrower than that of the subsequent experiments (Table 3).

Table 3 Wild-type Amblyseius deleoni resistance tests against $56 \% \mathrm{C}_{u} \mathrm{O}$.

\begin{tabular}{ccccc}
\hline Generation & $\mathbf{N}$ & $\begin{array}{c}\text { Range of concentrations } \\
(\mathbf{p p m})\end{array}$ & $\begin{array}{c}\mathbf{L C}_{\mathbf{5 0}}(\mathbf{9 5} \% \mathbf{~ F L}) \\
\mathbf{( \mathbf { p p m } )}\end{array}$ & $\begin{array}{c}\text { Slope } \pm \text { SE } \\
(\mathbf{p p m})\end{array}$ \\
\hline Wild type & 300 & $0.00-10.00$ & $\begin{array}{c}60.63 \\
(36.77-395.21)\end{array}$ & $1.033 \pm 0.121$ \\
\hline
\end{tabular}

Table 3 shows that the results of analysis of the exposures of the wild-type population against $\mathrm{C}_{\mathrm{u}} \mathrm{O}$ range of FL was overlapping, with more or less similar slopes. Souza-Pimentel et al. [21] suggested that exposure to the active fungicides mandipropamid, mefenoxam and difenoconazole was less toxic to the predatory mites Phytoseiulus macropilis (Banks) and Neoseiulus californicus (McGregor) (Acari: Phytoseiidae). The difference in the results of this study is most likely to be caused by the type of active fungicide compound rather than the species differences, since both predatory mites belong to the same family (Phytoseiidae) as the one used in this study. Based on the narrow range and overlapping values, the sample population from the test was used for subsequent selection tests of $A$. deleoni against $\mathrm{C}_{\mathrm{u}} \mathrm{O}$, and was then designated as a parent population. The results of the selection of $A$. deleoni against $56 \% \mathrm{C}_{\mathrm{u}} \mathrm{O}$ up to generation 12 are presented in Table 4.

Table 4 The increasing resistance of Amblyseius deleoni against $56 \% \mathrm{C}_{\mathrm{u}} \mathrm{O}$ from Parent generation (P) to $12^{\text {th }}$ generation (F12).

\begin{tabular}{ccccc}
\hline Generation & $\begin{array}{c}\text { LC }_{\mathbf{5 0}}(\mathbf{9 5} \mathbf{\%} \text { Fiducial Limit) } \\
(\mathbf{p p m})\end{array}$ & $\begin{array}{c}\text { Resistance } \\
\text { Ratio }\end{array}$ & $\begin{array}{c}\text { Slope } \pm \text { SE } \\
(\mathbf{p p m})\end{array}$ & $\boldsymbol{\chi}^{\mathbf{2}} \mathbf{( \mathbf { d f } = \mathbf { 2 2 } )}$ \\
\hline P & $60.63(36.770-395.21)^{\mathrm{a}}$ & 1 & $1.03 \pm 0.12$ & 12.0394 \\
F1 & $77.61(47.76-121.54)^{\mathrm{a}}$ & 1.28 & $1.03 \pm 0.12$ & 17.8839 \\
F2 & $125.97(63.08-231.38)^{\mathrm{a}}$ & 2.08 & $0.67 \pm 0.09$ & 5.7035 \\
F3 & $245.90(137.40-431.75)^{\mathrm{a}}$ & 4.06 & $0.74 \pm 0.09$ & 6.4921 \\
F4 & $907.03(456.09-2066.97)^{\mathrm{b}}$ & 14.96 & $0.58 \pm 0.08$ & 7.3463 \\
F5 & $3328.80(2074.00-5583.12)^{\mathrm{c}}$ & 54.91 & $1.11 \pm 0.13$ & 28.756 \\
F6 & $8043.28(5869.26-11368.00)^{\mathrm{d}}$ & 132.67 & $1.26 \pm 0.19$ & 4.7088 \\
F7 & $13929.21(11840.20-16846.50)^{\mathrm{e}}$ & 229.75 & $2.22 \pm 0.26$ & 20.1566 \\
F8 & $22712.15(19612.4-26111.5)^{\mathrm{f}}$ & 374.62 & $3.48 \pm 0.37$ & 20.7412 \\
F9 & $34762.00(29952.70-40305.25)^{\mathrm{g}}$ & 573.37 & $3.09 \pm 0.39$ & 9.1361 \\
\end{tabular}




\begin{tabular}{ccccc}
\hline Generation & LC $\mathbf{5 0}(\mathbf{9 5}$ \% Fiducial Limit) & $\begin{array}{c}\text { Resistance } \\
\text { (ppm) }\end{array}$ & $\begin{array}{c}\text { Slope } \pm \text { SE } \\
\text { Ratio }\end{array}$ & $\boldsymbol{\chi}^{\mathbf{2}(\mathbf{d f}=\mathbf{2 2})}$ \\
\hline F10 & $46261.10(41166.80-51308.92)^{\mathrm{h}}$ & 763.03 & $4.27 \pm 0.49$ & 4.0731 \\
F11 & $77223.90(72009.50-82615.67)^{\mathrm{i}}$ & 1273.73 & $6.81 \pm 0.78$ & 5.8537 \\
F12 & $84676.59(77740.60-90690.30)^{\mathrm{i}}$ & 1396.66 & $7.32 \pm 1.00$ & 6.7008 \\
\hline
\end{tabular}

Note: The number of individuals $(\mathrm{N})$ in each generation was 300. FL (Fiducial Limit) is the upper and lower limits of the range of pesticide concentrations with a confidence limit of $95 \%$. The values of $95 \%$ FL followed by the same small letters, indicated that there is no significant difference, based on statistical tests using POLO $(P>0.05)$.

The results of statistical analysis using POLO showed that the $\mathrm{LC}_{50}$ between the parent generations, F1, F2 and F3 were not significantly different $\left(P>0.05\right.$, overlapping ranges of FL $\left.\mathrm{LC}_{50}\right)$. Based on the comparison of $\chi^{2}$ values against $\chi^{2}$ in the statistical table, it is indicated that the populations of Parent to F3 were dominated by individuals that were susceptible to the pesticide, and proportions of the resistant individuals were very low (slope $=1.033$ in parent population). However, the exposure to this pesticide in the subsequent experiments resulted in the increasing proportion of resistant individuals, indicated by a significant difference among $\mathrm{FL} \mathrm{LC}_{50}$ values of $A$. deleoni $(P<0.05)$. Accordingly, the level of resistance (resistance ratio) increased by 14.96 times in generation F4 compared to that of the parent. The increasing proportion of the resistant individuals occurred until $10^{\text {th }}$ generation (F10). Afterwards, the proportion of resistant individuals from F11 - F12 only slightly increased.

The increasing ratio of resistance levels to reach 1396.66 times in $12^{\text {th }}$ generation higher than that of the parent indicated that the predatory mite $A$. deleoni was highly tolerant to $\mathrm{C}_{\mathrm{u}} \mathrm{O}$ fungicide. Thus, this type of fungicide is not harmful to the survival of these predatory mites. Similar results were also reported by Souza-Pimentel et al. [21], although the active fungicide compounds and the predatory mites species used were different. In addition, Souza-Pimentel et al. [21] found that penetration of $\mathrm{C}_{\mathrm{u}} \mathrm{O}$ through the cuticle could cause the chemoreceptors organ to form a permeability barrier in the cuticle to be more selective. Furthermore, the cuticle of predatory mites contains many sterols that reduce its permeability to water and fungicides. However, continuous fungicide selection pressure on the predatory mites from generation to generation can cause the chemoreceptor organs to become thicker and more sensitive $[5,10]$.

The results of resistance tests on the wild-type population of $A$. deleoni against neem seed extract (Table 5).

Table 5 The results of resistance tests on the wild-type population of $A$. deleoni against neem seed extract.

\begin{tabular}{ccccc}
\hline Generation & $\mathbf{N}$ & $\begin{array}{c}\text { Range of concentration } \\
(\mathbf{p p m})\end{array}$ & $\begin{array}{c}\mathbf{L C}_{\mathbf{5 0}}(\mathbf{9 5} \mathbf{\%} \mathbf{\text { FL}}) \\
(\mathbf{p p m})\end{array}$ & $\begin{array}{c}\text { Slope } \pm \text { SE } \\
(\mathbf{p p m})\end{array}$ \\
\hline Wild type & 300 & $0.00-100$ & 25.33 & $5.833 \pm 0.933$ \\
& & & $(21.68-28.34)$ & \\
\hline
\end{tabular}

Based on the narrow and overlapping range of $\mathrm{FL} \mathrm{LC}_{50}$ values, the wild-type population was then designated as the parent population, and was used in the subsequent selection tests of $A$. deleoni against neem seed extract (Table 6).

Table 6 Increasing resistance level of Amblyseius deleoni against neem extract from generation to generation.

\begin{tabular}{ccccc}
\hline Generation & $\begin{array}{c}\mathbf{L C}_{\mathbf{5 0}}(\mathbf{9 5} \mathbf{\%} \mathbf{F L}) \\
(\mathbf{p p m})\end{array}$ & $\begin{array}{c}\text { Resistance } \\
\text { Ratio }\end{array}$ & $\begin{array}{c}\text { Slope } \pm \text { SE } \\
(\mathbf{p p m})\end{array}$ & $\boldsymbol{\chi}^{\mathbf{2}(\mathbf{d f}=\mathbf{2 2})}$ \\
\hline P & $24.67(21.19-27.46)^{\mathrm{a}}$ & 1.00 & $6.163 \pm 1.063$ & 6.7694 \\
F1 & $27.62(24.44-30.52)^{\mathrm{a}}$ & 1.12 & $6.168 \pm 0.868$ & 10.0704 \\
F2 & $30.25(26.46-33.69)^{\mathrm{a}}$ & 1.23 & $5.094 \pm 0.622$ & 8.4714 \\
F3 & $32.83(29.16-36.29)^{\mathrm{a}}$ & 1.33 & $5.321 \pm 0.607$ & 9.3795 \\
F4 & $36.93(33.46-40.35)^{\mathrm{a}}$ & 1.49 & $6.107 \pm 0.644$ & 10.420
\end{tabular}




\begin{tabular}{|c|c|c|c|c|}
\hline Generation & $\begin{array}{c}\mathrm{LC}_{50}(95 \% \mathrm{FL}) \\
(\mathrm{ppm})\end{array}$ & $\begin{array}{c}\text { Resistance } \\
\text { Ratio }\end{array}$ & $\begin{array}{l}\text { Slope } \pm \text { SE } \\
(\text { ppm })\end{array}$ & $\chi^{2}(\mathbf{d f}=22)$ \\
\hline F5 & $45.86(41.31-50.37)^{b}$ & 1.86 & $5.787 \pm 0.576$ & 25.986 \\
\hline F6 & $48.73(44.23-53.21)^{b}$ & 1.98 & $5.114 \pm 0.523$ & 19.9165 \\
\hline F7 & $49.77(44.49-55.08)^{b}$ & 2.02 & $4.699 \pm 0.494$ & 24.941 \\
\hline F8 & $49.85(44.87-54.88)^{b}$ & 2.02 & $4.849 \pm 0.502$ & 23.296 \\
\hline
\end{tabular}

Note: The number of individuals $(\mathrm{N})$ in each generation was 300. FL (Fiducial Limit) is the upper and lower limits of the range of pesticide concentrations with a confidence limit of $95 \%$. The values of $95 \%$ FL followed by the same small letters, indicated that there is no significant difference, based on statistical tests using POLO $(P>0.05)$.

Exposure to the neem seed extracts noticeably increased the proportion of the resistant individuals in F1, F2, F3 and F4 generations, to be more tolerant in the $5^{\text {th }}$ (F5) generation, indicated by the nonoverlapping range of FL LC $\mathrm{L}_{50}$ and the decreasing values of the slopes (Table 6). The increase in tolerant levels of $A$. deleoni towards the neem seed extracts occurred gradually and finally reached 2.02 times in generations F7 and F8 compared to the tolerant level of the parent population. Accordingly, the proportion of homogeneity of the tolerant individuals increased, indicated by the decrease in the slope value in the generation $\mathrm{F} 8$.

The compounds in the neem extract used in this research seemed to contribute similar selection pressures, but caused different impacts, depending on the target individuals and the concentration. This is in accordance with [8] and [5] that the neem seed extract contains various compounds including azadiradione, azadirone, nimbin and salannin, but only azadirachtin acts as a strong antifeedant. In addition, according to Gahukar [4], different enzymes may catalyze various oxidative reactions of many compounds in the neem extracts. Supposedly, the resistance against neem extracts may continue and develop due to the genetic variations in a population and continuous selection pressures [20].

In this study, we have successfully developed resistant populations of predatory mite $A$. deleoni against propargite acaricide, $56 \% \mathrm{C}_{\mathrm{u}} \mathrm{O}$ and neem seed extracts. However, we need to test whether or not these pesticide exposures also changed the feeding behavior of the resistant populations of A. deleoni. For these purposes, several tests were conducted to study their feeding behaviors.

Regarding the feeding preference, the results showed that the propargite-resistant population of $A$. deleoni preferred $T$. urticae than other alternative prey. This preference was not significantly different from that of the control population (wild type), which had not been exposed to propargite (Table 7). A similar phenomenon was also found in resistant populations to $56 \% \mathrm{C}_{\mathrm{u}} \mathrm{O}$ (Table 8) and to neem-seed extracts (Table 9).

Table 7 The preference of propargite-resistant predatory mites Amblyseius deleoni on several alternative preys (data were transformed with $\sqrt{ } \mathrm{x}+0.5$ ).

\begin{tabular}{ccc}
\hline \multirow{2}{*}{ Types of food } & \multicolumn{2}{c}{ Number of individuals consumed \pm SD/24 h } \\
\cline { 2 - 3 } & $\boldsymbol{A}$. deleoni (Control) & A. deleoni (propargite resistant) \\
\hline Tetranychus urticae & $2.78 \pm 0.35$ a A & $3.28 \pm 0.52$ a A \\
Tea Pollen & $2.84 \pm 0.38$ a A & $2.73 \pm 0.49$ a A \\
Red bean Pollen & $1.51 \pm 0.25 \mathrm{~b} \mathrm{~A}$ & $1.56 \pm 0.69 \mathrm{~b} \mathrm{~A}$ \\
Tyrophagus sp. & $1.86 \pm 0.48 \mathrm{~b} \mathrm{~A}$ & $1.12 \pm 0.55 \mathrm{~b} \mathrm{~A}$ \\
\hline
\end{tabular}

Note: The numbers in the same column, followed by different letters indicate a significant difference with $P=0.05$, while the numbers in the same row followed by the same capital letters, indicates that there is no significant difference $P=0.05$. 
Table 8 Feeding preference of predatory mites Amblyseius deleoni resistant to $56 \% \mathrm{C}_{\mathrm{u}} \mathrm{O}$ on alternative foods, (the data was transformed with $\sqrt{\mathrm{x}}+0.5$ ).

\begin{tabular}{|c|c|c|}
\hline \multirow{2}{*}{ Types of food } & \multicolumn{2}{|c|}{ Average number of individuals consumed $\pm \mathrm{SD} / 24 \mathrm{~h}$} \\
\hline & A. deleoni (Control) & $56 \% \mathrm{C}_{\mathrm{u}} \mathrm{O}$ resistant $A$. deleoni \\
\hline Tetranychus urticae & $2.78 \pm 0.35$ a A & $2.66 \pm 0.52$ a A \\
\hline Tea Pollen & $2.84 \pm 0.38$ a $\mathrm{A}$ & $3.22 \pm 0.37 \mathrm{~b} \mathrm{~A}$ \\
\hline Red bean pollen & $1.51 \pm 0.25 \mathrm{~b} \mathrm{~A}$ & $1.26 \pm 0.32$ c A \\
\hline Tyrophagus sp. & $1.86 \pm 0.48 \mathrm{~b} \mathrm{~A}$ & $1.58 \pm 0.46 \mathrm{c} \mathrm{A}$ \\
\hline
\end{tabular}

Note: The numbers in the same column followed by different letters indicate a significant difference with $P=0.05$, while the numbers in the same row followed by the same capital letters, indicates that there is no significant difference $P=0.05$.

Table 9 Feeding preference of predatory mites Amblyseius deleoni resistant to neem extract on alternative foods, (data was transformed with $\sqrt{ } \mathrm{x}+0.5$ ).

\begin{tabular}{lcc}
\hline \multicolumn{1}{c}{ Types of food } & \multicolumn{2}{c}{$\begin{array}{c}\text { Average number of individuals consumed } \pm \mathbf{S D} / \mathbf{2 4} \mathbf{~ h} \\
\text { Neem extract resistant } \boldsymbol{A} \text {. deleoni }\end{array}$} \\
\hline Tetranychus urticae & $2.78 \pm 0.35$ a A & $2.88 \pm 0.68$ a A \\
Tea pollen & $2.84 \pm 0.38$ a A & $2.53 \pm 0.54$ ab A \\
Red bean pollen & $1.51 \pm 0.25 \mathrm{~b} \mathrm{~A}$ & $2.09 \pm 0.59 \mathrm{bc} \mathrm{A}$ \\
Tyrophagus sp. & $1.86 \pm 0.48 \mathrm{~b} \mathrm{~A}$ & $1.40 \pm 0.19 \mathrm{c} \mathrm{A}$ \\
\hline
\end{tabular}

Note: The numbers in the same column followed by different letters indicate a significant difference with $P=0.05$, while the numbers in the same row followed by the same capital letters, indicates that there is no significant difference $P=0.05$.

The prey preference (Table 9) of the resistant population of A. deleoni on $T$. urticae might indicate that the selection pressure of propargite favored the individuals with more sensitive chemoreceptor organs. This finding is in accordance to Fiedler and Sosnowska [18] who found similar results on Phytoseius sp. Correspondingly, since propargite has the residual killing action, thus the individuals with more sensitive chemoreceptor organs also possessed less permeable integuments so they were able to minimize the penetration of toxicants to reduce the toxic effects. The selective permeability barrier of the integument relates to the balance between hydrophilic character of the integument and the toxicants that are mostly lipophilic, so the toxicants will stay in or around the membrane of the chemoreceptor organs [3]. Calvo et al. [10] assumed that the reduction of the penetration of toxic substances through the integument involves enzymatic oxidative biotransformation. The increased sensitivity of chemoreceptor organs of propargite-resistant predatory mites may have improved the responsiveness of the mites to the existence and the movement of $T$. urticae than other alternative prey such as Tyrophagus sp. tea and red bean pollen [20,21].

Regarding the predatory capacity, we also found that $A$. deleoni did not change after being exposed to the selection pressures of propargite, $56 \% \mathrm{C}_{\mathrm{u}} \mathrm{O}$ and neem extracts (Tables 10 - 12).

Table 10 Predatory capacity of propargite-resistant Amblyseius deleoni on alternative foods (the data were transformed with $\sqrt{x}+0.5)$.

\begin{tabular}{lcc}
\hline \multirow{2}{*}{ Food (T. urticae) } & \multicolumn{2}{c}{ Average number of individuals consumed \pm SD/24 h } \\
\cline { 2 - 3 } & $\boldsymbol{A .}$ deleoni (control) & $\boldsymbol{A}$. deleoni (propargite resistant) \\
\hline Egg & $2.09 \pm 0.21$ a A & $1.90 \pm 0.11$ a A \\
Larva & $2.15 \pm 0.18$ a A & $2.41 \pm 0.07 \mathrm{~b} \mathrm{~B}$ \\
Nymph & $1.18 \pm 0.23 \mathrm{~b} \mathrm{~A}$ & $1.51 \pm 0.18 \mathrm{c} \mathrm{B}$ \\
Adult & $1.02 \pm 0.14 \mathrm{~b} \mathrm{~A}$ & $0.94 \pm 0.13 \mathrm{~d} \mathrm{~A}$ \\
\hline
\end{tabular}

Note: The numbers in the same column, followed by different letters indicate a significant difference with $P=0.05$, while the numbers in the same row followed by the same capital letters, indicates that there is no significant difference $P=0.05$. 
Table 11 Predatory capacity of predatory mites Amblyseius deleoni resistant to $56 \% \mathrm{C}_{\mathrm{u}} \mathrm{O}$ on alternative foods (the data were transformed with $\sqrt{ } \mathrm{x}+0.5$ ).

\begin{tabular}{ccc}
\hline \multirow{2}{*}{ Food (various stages of $\boldsymbol{T}$. urticae) } & \multicolumn{2}{c}{ Average number of individuals consumed \pm SD/24 h } \\
\cline { 2 - 3 } & A. deleoni (control) & A. deleoni $\left(\mathbf{C}_{\mathrm{u}} \mathbf{O} \mathbf{5 6} \%\right.$ resistant) \\
\hline Egg & $2.09 \pm 0.21 \mathrm{a} \mathrm{A}$ & $1.29 \pm 0.31 \mathrm{a} \mathrm{A}$ \\
Larva & $2.15 \pm 0.18$ a A & $2.18 \pm 0.26$ a A \\
Nymph & $1.18 \pm 0.23 \mathrm{~b} \mathrm{~A}$ & $1.29 \pm 0.31 \mathrm{~b} \mathrm{~A}$ \\
Adult & $1.02 \pm 0.14 \mathrm{~b} \mathrm{~A}$ & $1.02 \pm 0.14 \mathrm{~b} \mathrm{~A}$ \\
\hline
\end{tabular}

Note: The numbers in the same column followed by different letters indicate a significant difference with $P=0.05$, while the numbers in the same row followed by the same capital letters, indicates that there is no significant difference $P=0.05$.

Table 12 Predatory capacity of mites Amblyseius deleoni resistant to neem extracts on alternative foods (the data were transformed with $\sqrt{ } \mathrm{x}+0.5$ ).

\begin{tabular}{|c|c|c|}
\hline \multirow{2}{*}{$\begin{array}{c}\text { Food (various stages of } \\
\text { T. urticae) }\end{array}$} & \multicolumn{2}{|c|}{ Average number of individuals consumed $\pm \mathrm{SD} / 24 \mathrm{~h}$} \\
\hline & A. deleoni (control) & A. deleoni (neem extract resistant) \\
\hline Egg & $2.09 \pm 0.21 \mathrm{a} \mathrm{A}$ & $2.25 \pm 0.17 \mathrm{a} \mathrm{A}$ \\
\hline Larva & $2.15 \pm 0.18$ a A & $2.06 \pm 0.21 \mathrm{~b} \mathrm{~A}$ \\
\hline Nymph & $1.18 \pm 0.23 \mathrm{~b} \mathrm{~A}$ & $1.51 \pm 0.18$ c B \\
\hline Adult & $1.02 \pm 0.14 \mathrm{~b} \mathrm{~A}$ & $1.05 \pm 0.20 \mathrm{~d} \mathrm{~A}$ \\
\hline
\end{tabular}

Note: The numbers in the same column followed by different letters indicate a significant difference with $P=0.05$, while the numbers in the same row followed by the same capital letters, indicates that there is no significant difference $P=0.05$.

Tables 10 - 12 show that although the selection pressures of propargite, $56 \% \mathrm{C}_{\mathrm{u}} \mathrm{O}$ and neem seed extracts caused changes in the predatory capacity, however, the positive-response stimulating power was not strong enough to significantly change the feeding behavior of predatory level of predatory mites $A$. deleoni. These responses were more towards merely adaptive reactions under a selection pressure of the pesticides used in this study. Thus, the selection pressure of propargite, $56 \% \mathrm{C}_{\mathrm{u}} \mathrm{O}$ and neem seed extracts did not significantly modify the feeding preference of $A$. deleoni on $T$. urticae. Thus, these resistances appeared to be a phenomenon of adaptive reaction [8] as suggested by Michalska [22] and Silva et al. [23] who argued that based on the lethal and sublethal toxicity analysis approach, it was known that the active compound of neem was selective against the predatory mite Proprioseiopsis neotropicus (Acari: Phytoseiidae).

\section{Conclusions}

The selection pressures resulted in the predatory mites $A$. deleoni to develop resistance against propargite, $56 \% \mathrm{C}_{\mathrm{u}} \mathrm{O}$ and neem seed extracts, but did not affect the feeding preference and the predatory capacity of the mite $A$. deleoni on $T$. urticae.

\section{Acknowledgements}

The authors would like to thank the Ministry of Research, Technology and Higher Education of Indonesia for the National Strategic Research Grant.

\section{References}

[1] BH Budianto and E Basuki. The predatory ability of temperature resistant Amblyseius sp. to Tetranychus urticae (in Indonesian). J. Hama Penyakit Tumbuh. Trop. 2013; 13, 35-41.

[2] JJ Park, M Kin, JH Lee, K Shin, SE Lee, JG Kim and K Cho. Sublethal effects of fenpyroximate and pyridaben on two predatory mite species, Neoseiulus womersleyi and Phytoseiulus persimilis (Acari, Phytoseiidae). Exp. Appl. Acarol. 2011; 54, 243-59.

[3] RRD Silva, AV Teodoro, MDJS Silva, PR Reis and SS Silva. Compatibility of pesticides with the generalist predatory mite Amblyseius largoensis (Acari: Phytoseiidae). Rev. Colomb. Entomol. $2015 ; \mathbf{4 1}, 76-80$. 
[4] RT Gahukar. Plant-derived products in crop protection: Effects of various application methods on pests and diseases. Phytoparasitica 2016; 44, 379-91.

[5] MT Fountain and N Medd. Integrating pesticides and predatory mites in soft fruit crops. Phytoparasitica 2015; 43, 657-67.

[6] X Zhang, J Lv, Y Hu, B Wang, X Chen, X Xu and E Wang. Prey Preference and life table of Amblyseius orientalis on Bemisia tabaci and Tetranychus cinnabarinus. PLoS One 2015; 10, $\mathrm{e} 0138820$.

[7] CC Childers and HA Denmark. Phytoseiidae (Acari: Mesostigmata) within citrus orchards in Florida: species distribution, relative and seasonal abundance within trees, associated vines and ground cover plants. Exp. Appl. Acarol. 2011; 54, 331-71.

[8] FR Afshar and M Latifi. Functional response and predation rate of Amblyseius swirskii (Acari: Phytoseiidae) at three constant temperatures. Persian J. Acarol. 2017; 6, 299-314.

[9] M Maroufpoor, Y Ghoosta and AA Pourmirza. Toxicity of diazinon and acetamipridon on life table parameters of the predatory mite, Neoseiulus californicus (Acari: Phytoseiidae) when fed on the European red mite Panonychus ulmi (Koch). Egypt. J. Biol. Pest Control 2016; 26, 15-9.

[10] FJ Calvo, M Knapp, YMV Houten, H Hoogerbrugge and JE Belda. Amblyseius swirskii: What made this predatory mite such a successful biocontrol agent? Exp. Appl. Acarol. 2015; 65, 419-33.

[11] EMA El-Saiedy, MF Hassan, AF El-Bahrawy, GA El-Kady and MS Kamel. Efficacy of two phytoseiid predators and a biopesticide against Tetranychus cucurbitacearum (Sayed) (Acari: Tetranychidae) on eggplant at Ismailia Governorate, Egypt. Egypt. J. Biol. Pest Control 2015; 25, $71-4$.

[12] A Janssen and MW Sabelis. Alternative food and biological control by generalist predatory mites: the case of Amblyseius swirskii. Exp. Appl. Acarol. 2015; 65, 413-8.

[13] I Goleva and CPW Zebitz. Suitability of different pollen as alternative food for the predatory mite Amblyseius swirskii (Acari, Phytoseiidae). Exp. Appl. Acarol. 2013; 61, 259-83.

[14] A Midthassel, SR Leather and IH Baxter. Life table parameters and capture success ratio studies of Typhlodromips swirskii (Acari: Phytoseiidae) to the factitious prey Suidasia medanensis (Acari: Suidasidae). Exp. Appl. Acarol. 2013; 61, 69-78.

[15] EK Puchalska and M Kozak. Typhlodromus pyri and Euseius finlandicus (Acari: Phytoseiidae) as potential biocontrol agents against spider mites (Acari: Tetranychidae) inhabiting willows: Laboratory studies on predator development and reproduction on four diets. Exp. Appl. Acarol. 2016; 68, 39-53.

[16] S Parsa, NA Hazzi, Q Chen, F Lu, BVH Campo, JS Yaninek and AA Vasquez-Ordonez. Potential geographic distribution of two invasive cassava green mites. Exp. Appl. Acarol. 2015; 65, 195-204.

[17] DL Mutisya, EM El-Banhawy, CPM Khamala and CW Kariuki. Management of cassava green mite Mononychellus progresivus (Acari: Tetranychidae) in different agro-ecological zones of Kenya. Syst. Appl. Acarol. 2015; 20, 39-50.

[18] Z Fiedler and D Sosnowska. Side effects of fungicides and insecticides on predatory mites, in laboratory conditions. J. Plant Prot. Res. 2014; 54, 349-53.

[19] LC Hewitt, L Shipp, R Buitenhuis and C Scott-Dupree. Seasonal climatic variations influence the efficacy of predatory mites used for control of western flower thrips in greenhouse ornamental crops. Exp. Appl. Acarol. 2015; 65, 435-50.

[20] FSA Mohamed, HE Hussein, ZEA Darwish, SAA Amer, AB Salama and ME El-Desouky. Influence of some extracts from three lamiaceae plants on toxicity, repellency and some biological aspects of Tetranychus urticae koch (Acari: Tetranychidae). Egypt. J. Biol. Pest Control 2015; 25, 255-160.

[21] GC Souza-pimentel, PR Reis, PDP Marafeli and JP Alves. Physiological selectivity of agrochemicals to predatory mites of Tetranychus urticae (Acari: Tetranychidae) on rosebushes growing in greenhouse. Int. J. Environ. Agric. Res. 2017; 3, 14-22.

[22] K Michalska. The effect of predation risk on spermatophore deposition rate of the eriophyid mite, Aculops allotrichus. Exp. Appl. Acarol. 2016; 68, 145-54.

[23] ACB Silva, AV Teodoro, EE Oliveira and AGS Maciel. Lethal and sublethal effects of neem oil to the predatory mite Proprioseiopsis neotropicus (Acari: Phytoseiidae). Rev Colomb. Entomol. 2013; 39, 221-5. 